This is an Accepted Manuscript of an article published by Taylor \& Francis in Teaching in Higher Education, on 12 July 2016, available online: http://www.tandfonline.com/10.1080/13562517.2016.120762\$

\title{
Supporting business students' transition into Higher Education: the case of Marketing Downloads
}

Deborah Anderson, Hilary Wason and Jane Southall

Kingston Business School, Kingston University, Kingston upon Thames, UK KT2 7LB.

Corresponding author: D.Anderson@kingston.ac.uk

\begin{abstract}
This paper discusses a student-centred learning and teaching approach, 'Marketing Downloads', designed to support students in transition into Higher Education. The move from secondary to tertiary education can be stressful for students and it impacts on their academic performance, their social life and general sense of well-being. Marketing Downloads was designed with transition in mind and involves students initiating their own research to demonstrate the link between theory and real-world business practice, presenting their work and instigating a debate. Evaluation of data from five focus groups suggests that the social nature, the secure environment, the student-centred aspect and the links with the outside world help students understand the difference between secondary and tertiary education and ultimately contribute to a smooth transition. Recommendations for learning and teaching initiatives focus on these four aspects: a safe classroom environment, social networks, student-centred exercises and creating links to the outside world.
\end{abstract}

Key words: transitions, teaching initiatives, student-centred learning

\section{Introduction}

The importance of a smooth transition into the first year of tertiary education is well documented as it impacts on a student's academic performance, their social life and general sense of well-being (e.g., Tinto 2003; Zajacova, Lynch and Espenshade 2005; Leary and DeRosier 2012). Johnston (2010) highlights the importance of universities offering students a first year that meets their expectations, sparks engagement and encourages high standards of efforts and achievement. He believes that university education should empower students for participation in their studies, employment and lifelong learning. Business students also need to apply academic concepts to the real world from the start, in order to build the skills that future employers demand (Finch, Nadeau and O'Reilly 2012).

This paper discusses a student-centred learning and teaching approach, 'Marketing Downloads', that has been developed and evaluated at a UK business school to support students with their transition to tertiary education. The development of the approach began with a review of the literature, presented below. Based on this, an initiative was designed with the aim of increasing levels of student confidence and engagement, developing efficient independent learning skills, and enabling students to create their learner identity. It was also intended to support students in applying their new, class-room based knowledge to the wider world of business. The initiative and its evaluation are explained in more detail. This is followed by discussion, conclusions and a statement of the implications for educators. 


\section{Literature review}

According to the literature, a new type of student and a new tertiary education environment are emerging (Prichard 2006). Students are entering university from a diverse range of demographic and attitudinal backgrounds with a correspondingly wide range of needs which institutions must consider (Archer 2007). These new students have a different learning experience and skill set from previous generations. They have developed in a secondary educational environment where the focus is often on 'spoon feeding' information in order to pass exams and where there is less need for them to develop as autonomous and reflective learners (Haggis 2006; Pokorny and Pokorny 2006). Consequently, for many, the move to Higher Education (HE) can be likened to entering an 'alien' environment (Aksham 2008) and the transition period is challenging. This can be worse for first-in-family HE students. Studies (e.g., McMillen 2014) show that traditional students, who come from families where HE is seen as the norm, are generally better equipped in terms of confidence and security in their abilities. Such families are often able to access secondary education which focusses on developing independent learning skills and, in addition, can often offer increased levels of financial and emotional support.

Walton and Cohen $(2007 ; 2011)$ have identified that students who lack positive connections with others are likely to under-achieve academically. Fear of social isolation and of not fitting in can often lead to students establishing any form of contact, whether positive or negative, appropriate or inappropriate, so as not to be seen to be alone (Fisher, Cavanagh and Bowles 2011; Maunder, Cunliffe and Galvin 2013). In addition to this fear of loneliness, "friendsickness" can be an issue for many as they go through a grieving process for the loss of pre-university contacts and relationships (Palmer, O'Kane and Owens 2009).

A student's ability to cope with stress is strengthened by the social support they think they will get (Leary and DeRosier 2012). The concept of 'bridging social capital' discussed by Putnam (2000) cited in Schuller, Baron and Field, (2000 p.10), identifies that students who feel central to a network of social learning relationships with lecturers and with fellow students have an increased feeling of connectedness and more confidence in their ability to learn. According to Tett and Maclachlan (2007), who draw on this earlier work, students feel a stronger sense of self-efficacy if they can develop these positive networks within a learning environment based on trust with a reciprocal approach to learning and teaching. The importance of student self-efficacy and its link to academic motivation and performance is also well-documented. Self-efficacy is defined as 'the levels of confidence individuals have in their ability to execute a course of action or attain specific performance outcomes (Bandura 1977, 191). According to Hsieh, Sullivan and Guerra (2007), confident students are more likely to initiate new things, try harder, persevere more when things get difficult and try to master a new skill. Students arrive at university with a range of confidence levels, some believing that they already know how to learn autonomously based on their school performance, as measured by grades achieved. Zajacova, Lynch and Espenshade (2005) argue that the degree of a student's ability to cope with the issues commonly related to the first year at university is directly linked to academic resilience, in other words, their persistence and success with their academic studies. Leary and DeRosier (2012) recommend that it is crucial to build students' emotional resilience during transition and that social identity can lead to academic success and ultimately increased retention. Their emotional outlook, a positive coping style and a feeling of being in control of their environment can promote resilience and provide the motivation needed to achieve social and academic goals. Turner (2014) identifies that self-belief is important for performance. In the context of employability, she notes that self-belief enables action and needs to be developed alongside 
skills within the curriculum. In this way, self-belief has significant impact on academic achievement.

Underpinning many of the recommendations for successful transition is the notion of studentcentred learning. Whilst Tangey (2014) suggests that there is not yet a specific definition for student-centred learning, it is broadly associated with the active learning principle and empowers students to take charge. McCabe and O'Connor (2014) highlight that a studentcentred learning approach encourages students to take more responsibility for their learning, and involves moving away from the traditional approach of lecturers instructing students and moving towards viewing lecturers as facilitators. In this approach, the co-operative nature of students participating with each other is highlighted. Taking a view of student-centred learning further, Turner (2014) notes the importance of 'mastery experience' which in turn relates to students gaining success, improvement and control (p 598). Finally, as Peterson and Dover (2014) note, a key challenge when developing effective pedagogy is to integrate theory with the realities of the workplace. This is particularly important for business students studying marketing modules where the theory/practice gap is well documented (e.g., Stephens, Balan and Callaghan 2010; Harrigan and Hulbert 2011;), and the ability to make connections between aspects of their knowledge, such as those between conceptual models and arguments studied in the class-room and what is used by practitioners in industry is essential.

In summary, what is clear from a review of the current literature, is that pedagogic practices have shifted in recent years and that a fresh approach is needed to improve engagement and confidence, develop autonomy in the new type of learner and raise achievement levels within HE. This resonates with the earlier discussion regarding the changing nature of HE students and their need to develop self-efficacy and independent learning skills. A learning environment where students feel secure, confident and empowered to participate and acquire knowledge is key (McCabe and O'Connor 2014; Turner 2014). The aim is for students in transition to develop their academic voice and their learner identity in order to avoid any negative effects on retention and progression (Tangney 2014). They must also be able to see the connections between the theory they learn and its application in the wider world (Peterson and Dover 2014).

\section{Marketing Downloads}

Given the findings from the literature, it became clear that any teaching and learning initiative developed for students in transition needed to allow them to develop social bonds and develop autonomy in their learning whilst feeling supported and guided in the process. For business students undertaking marketing modules in particular, it also needs to allow the application of theory to the real world of marketing practitioners.

Marketing Downloads was developed with these criteria in mind. In brief, to complete a Marketing Download, students work in self-selected pairs to choose an example of marketing practice to present to their colleagues during the class. For example, they might have observed that a brand is using a potentially unethical approach in its advertising (maybe a fast food company targeting children with the use of free gifts) so they would present this to the class alongside reviewing some of the theory on advertising ethics. In addition to simply presenting the example, students are required to lead a discussion and debate, and this receives a small amount of credit towards the final grade. They receive formative feedback on the presentation from both their peers and summative feedback from the tutor. All materials are uploaded onto the virtual learning system (in this case Blackboard) for sharing 
and future reference. Students have complete freedom to choose the subject of their Marketing Download within the context of the module syllabus. They can also choose when they present their work as up to three Marketing Downloads take place each week over two semesters.

In order to help current learners understand the concept, students from the previous year's cohort are invited into the classroom at the start of the academic year to discuss their experiences and present their Marketing Downloads. Previous examples are also available on the virtual learning environment for reference. Students are briefed at the start of the year on the learning approach and are given regular positive encouragement to challenge themselves.

\section{Evaluation methodology}

Evaluation aimed to establish how a teaching initiative such as Marketing Downloads can contribute to a smooth transition to tertiary education. Given the "how" nature of the research question, evaluation was conducted using a qualitative approach. In order to gather a wide range of views, focus groups were selected as the method of data collection as they have the advantage of being able to generate substantial amounts of data in an efficient way (Robson 2011). This is supported by Silverman: 'Certainly open-ended interviews and focus groups can give you data much more quickly than observation and/or recording-although more slowly than text' (Silverman 2011, 160). In addition, 'participants are empowered and able to make comments in their own words, while being stimulated by thoughts and comments of others in the group' (Robson, 2011, 285).

The available population for the study was the whole cohort of students in their first year of study who had taken part in Marketing Downloads $(\mathrm{n}=80)$ as part of a Marketing Principles class. All students were invited to participate and in total five focus groups took place with 25 students attending in groups of five and these lasted approximately 45 minutes. A semistructured interview guide was produced to steer the discussions and included questions on skills developed and attitudes towards the initiative. In this way, respondents had an opportunity to express their feelings and opinions as well as introduce new concepts (Bryman and Bell 2011). Such flexibility is advantageous when a deep understanding of a phenomenon is required. Discussions were recorded and transcribed verbatim before the initial data reduction, which was achieved by the research team who coded the transcripts. Whilst some of the codes were deductive, derived from the semi-structured interview guide, several new concepts emerged, requiring the development of inductive codes. Initial open coding was followed by axial coding which involved interpreting the data by grouping fragmented data into categories to allow the eventual emergence of broad themes (Tracy 2013).

\section{Findings}

Findings are presented in the themes identified from the focus group analysis. Verbatim quotations are used to illustrate specific concepts as these serve to enliven the text, evoking the "voice" of the participants in a way which should improve the communicability of the results.

\section{The learning environment}

The social aspect of Marketing Downloads was a positive feature of all focus groups with strong support for the way in which the initiative encouraged students to get to know one another: 
I think the best thing is that it made everyone talk more, you got to know people on your course, a good little icebreaker'.

This was partly due to working with others to produce the Download, but also because there was an expectation that they would be required to stimulate discussion and debate. A strong feeling of wanting to get involved was a feature of all groups. A positive view of the low risk of speaking out in class meant that students were willing to participate and become involved in a way which was not apparent in other classes:

'It was nice because it takes a lot to make people speak in that class but during Marketing Downloads everyone wanted to get involved'.

Throughout all groups, it was clear that the environment created by the tutor, where students felt secure and unafraid to participate, was key to the positive views of the initiative. By ensuring students understood that Marketing Downloads was not about 'right' and 'wrong' answers they were able to relax and take part in the class:

'There's not really a wrong answer, less pressure on it.'

'Yeah it makes you just relax more after. Like okay it wasn't that bad, and then you can really start to enjoy what other people have to present to you as well.'

In turn, this then enabled students to reassure each other that the presentation and leading a debate was not as difficult as they thought. Overall, this safe environment appeared crucial:

'That's one of the main things that helped me was knowing that the environment was nice and I can go in and not be as nervous as I am going into other classes.'

Another explanation of students actively wanting to get involved could be the student-centred nature of the initiative. Participants appeared to enjoy learning from each other and seeing how they shared interests:

'Yeah actually it was really good to hear other people's work because their work was actually quite interesting so you're not only learning from your work but learning from others as well.'

By allowing total freedom of choice of topic for the Download, students appeared to feel responsible for their work in a way which may not be the case if the topic we allocated:

'No disrespect to the teacher but if they were to pick the topics for us then it may not have been as interesting.'

A dilemma occurred, however, in discussions about the briefing of Marketing Downloads and the issue of total choice. At first, students appeared not to understand what was required and expressed a desire for much more explanation:

'I found "where to begin" quite challenging.'

It was agreed that students who presented early in the semester were at a disadvantage as they had little on which to base their work (despite the examples given by the instructor and previous students). Once completed, however, there was a realisation that having less explicit guidance is part of studying at tertiary level: 
'I think that before university you don't have freedom. They tell what you do and they give you clear guidance. That's why at the start it was it was a bit more difficult to understand.'

This growing realisation of the difference between secondary and tertiary education with the deliberate withdrawal of explicit instruction became apparent in several of the groups.

Arguably this is one of the most important shifts in learning when moving from school to university and one of the most insightful findings about the role of Marketing Downloads in supporting transition.

\section{Reciprocity and supporting each other}

The notion of reciprocity featured in many of the discussions with numerous examples of students wanting to support each other:

'I think there was a bit of the "I'll ask a question on yours if you ask one on ours", we did do that.'

Because everyone in the class at some point would be required to stand up and present in front of the class, students appeared to want to support each other to make the exercise less stressful:

'You want to support them because they know how bad it is to stand up there and nobody answers your questions! It's so bad, so yeah, it's really good for the environment and everything.'

This clearly resulted in improved relationships with peers:

'And I was like ok I don't know you but then they keep answering questions so it builds a relationship within the class.'

\section{Skills acquired}

Presentation skills were highlighted by many participants, in particular the requirement to speak in a formal, professional style, and not to use colloquial language. There was also a realisation that to instigate a discussion and debate as part of the presentation, it is not enough to simply present some interesting examples. As one insightful participant observed:

'I think it's a skill as a presenter to not tell the audience everything and to allow them to make their own conclusions on your topics to which you may have some further information on.'

The possibility of being asked difficult questions by the audience also had some benefits:

'It helps you think on the spot, when people ask questions you have to think on the spot and answer straight away.'

Comments appear to demonstrate the added benefits of an initiative such as Marketing Downloads which requires students to stimulate discussion around their presentation. The student-centred aspect appears to enable students to think beyond merely presenting information but rather think about the reaction of their audience and potential questions, a meta-skill which will be of use in the workplace. As one participant observed:

'It's so much harder when you have to pull things out of the audience.' 
This was supported further by another comment:

'I'm learning how to ask good questions, based on before-unknown topics.'

The ability to develop an opinion and to take a critical stance when speaking out during a debate was highlighted by several participants:

'It gave me confidence to speak out against the motion as well, the confidence to disagree.'

As another participant noted:

'It's your own opinion. Which I think is really important when you go into the marketing industry you've got to know what you agree with.'

As well as being able to defend their own views, students also appreciated that there is skill involved in criticizing peers without appearing negative:

'Yeah you have to know how to put your point but at the same time criticize in a good way. You have to know how to ask a question.'

\section{Understanding links between theory and the outside world}

Marketing Downloads appears to have helped these first year students understand the subject, moving them from thinking simply of marketing as advertising and communications to a much broader conception. Participants explained how watching the Downloads and taking part in a discussion or debate helped them to deepen understanding by linking theory to examples:

'Because the "Converse" one shows how businesses try and position themselves, it helped me make the link. In theory I would understand it, but I wouldn't know how exactly they do it.'

Participants gave examples of how their thinking and ways of observing the world had changed outside the classroom:

'I look at products differently now after studying stuff. Yeah after doing Downloads I think "Oh, that's very interesting, I want to learn more about that kind of marketing!",

"Like today we were practising segmentation, targeting and positioning, like we had to think of an advert and before last year I probably wouldn't have paid much attention to them but now I pay more attention in case I have to use it in class."

One quotation sums this up succinctly:

'I also think that Marketing Downloads put your head in a marketing way of thinking, if you know what I mean.'

\section{Developing confidence}

Focus group discussions included several examples of how completing a Download developed their confidence: 
'...the scary thing was actually to talk about in front of the class especially when it was in the beginning of the class when we knew no one but it really did increase our confidence, honestly I mean we... I remember the day we left we felt like we were flying. I was so happy that we got people engaging and it just made me feel more confident as a speaker.'

The requirement to be able to answer questions from peers about the Download also helped in developing confidence:

'I think the most confidence you receive is when they're actually analyzing the Marketing Download and people are asking questions and answering them.'

Arguably this would not necessarily be the case with a straightforward presentation; the additional requirement to be able to stimulate debate, whilst initially challenging does result in feelings of self-efficacy and ultimately confidence.

\section{Discussion}

Given these findings, it is now possible attempt to understand in more depth how a teaching initiative such as Marketing Downloads can contribute to a smooth transition to tertiary education.

Palmer, O'Kane and Owens (2009) state that it is important for institutions to use approaches which build inclusion and allow relationships to develop. There is a body of evidence which suggests that even the shortest initiative which promotes cohesion can have long term benefits for social belonging and academic achievement (Walton and Cohen 2014). This study has enabled us to understand how this is possible. These findings suggest that by working in pairs, students are able to develop a relationship with one student but the requirement to then participate in discussion and the subsequent reciprocal support offered to peers seems to be contributing to stronger cohesion in the group. Focus group participants gave examples of how they were keen to ask questions which would support their peers and help them feel more comfortable, developing positive connections which would serve them well during the course. As Tett and Maclachlan (2007) argue, students who feel a central part of a network of social learning have an increased feeling of connectedness and confidence in their ability to learn. Feeling safe is an important element of this (McCabe and O'Connor 2014) and the findings suggest that a safe learning environment is nurtured by the Marketing Downloads initiative. Participants provided many examples of how they felt able to contribute to the class because of the secure environment. Part of this feeling of safety was the understanding that there was no right or wrong answer, but there was also an expectation that students would support each other through the process.

The findings do create the dilemma of how much freedom to allow the students in terms of the choice of topics for assessments. The unease expressed by respondents when guidelines were not totally explicit regarding the choice of topics reflects the concerns raised by Turner (2014) who noted that when students do not have enough information to make decisions, then there is a possibility that the circumstances can be stress-inducing ( $\mathrm{p} \mathrm{596).} \mathrm{This} \mathrm{needs} \mathrm{to} \mathrm{be}$ carefully considered when designing learning and teaching initiatives.

The need to spark engagement has been identified as one of the requirements of a successful first year (Johnston 2010) and findings from this study suggest that Marketing Downloads achieved this by creating a positive learning environment. A combination of students selecting the topics, having to lead their peers in discussion and debate and support each 
other, resulted in feelings of involvement and wanting to be involved. Findings suggest that students are developing their own academic voice through the initiative. By learning how to critically discuss their peers' work in a positive way, students appear to be moving away from being passive individuals to actively thinking students. There is further evidence that students are developing the ability to make connections between their studies and the outside world (as supported by Harrigan and Hulbert [2011]) as they cited several examples of how they were able to link the Marketing Downloads with marketing practice in business and industry.

Marketing Downloads appears to provide experiences which allow students to develop selfefficacy. For example, drawing on their own experiences of successfully carrying out a task and using observations of others as a benchmark are features of Marketing Downloads (Bandura 1997). Positive encouragement from others and feedback from someone who is seen as knowledgeable and reliable (such as the tutor) also contribute to the development of self-efficacy and increase students' belief in their ability to cope with the learning transition to an HE environment.

\section{Conclusion}

This study set out to explore if a learning and teaching initiative could be designed which would contribute to a smooth transition to tertiary education for business students. In-depth discussions with students have identified that Marketing Downloads, which is studentcentred, involves a network of social learning relationships and is linked to the outside world can provide opportunities for students to understand the learning transition from secondary to tertiary education.

Marketing Downloads appeared to generate a positive learning environment in which students felt relaxed and able to contribute without fear of getting things wrong. They seemed to enjoy supporting each other and having the ability to choose their topics. Although some stress and unease did occur due to the amount of freedom allowed, students recognized that at the end of the process, this represented the transition to more independent learning which is expected from them at tertiary level.

Arguably the student-centred aspect is crucial in that the same impact would not have been possible by simply asking students to present on a pre-defined topic. The important elements appear to have been the inclusion of student choice and the requirement to stimulate a discussion which ensured that students began to think about possible questions that they could pose, or alternatively to consider what questions they might be asked. This marks a fundamental difference between learning at a secondary and tertiary level, moving away from students as passive to active learners, introducing the concept of independent learning and reflection.

From a discipline point of view, the participants appeared to have made connections with the outside world, bringing the theory from the subject to life. By providing a safe environment in which students did not need to worry about getting something right, students appear to become more involved and in turn, end up feeling a greater sense of achievement.

\section{Recommendations}

From this study, it is proposed that the following principles should be considered when designing pedagogic approaches for students in their first year of HE study:

1. Provide a safe classroom environment where students are able to speak freely without fear of getting something wrong. 
2. Develop exercises which require students to engage with the whole class as well as smaller sub-groups. In this way they can increase their social networks and build relationships to support them through their course.

3. Ensure the approach is student-centred to enable students to take responsibility for their learning and begin the journey to independent learners, in other words to make the transition from secondary to tertiary education. Consider carefully, however, the extent of the freedom given to students in the assignment topic choice; enough to feel ownership, but not so much that students feel unable to make decisions.

4. Link activities to the outside world so that students can see the relevance of their studies.

\section{Limitations and further research}

As a qualitative study using a convenience sample, results are not generalizable across other research sites. In addition, since all students took part in a Download, it was not possible to highlight a control cell in order to do a comparative study of the impact of lack of participation or to compare Marketing Downloads against other initiatives aimed at improving transition. This could be the subject of future study. On the other hand, the research has provided rich insights into students experiencing transition and has developed an understanding of how learning and teaching initiatives can contribute to a smooth transition from secondary to tertiary education with workable, practical recommendations for educators. Whilst this example was used within a marketing module, it would be possible for other business modules and other practical disciplines to adopt a similar approach, where real life examples of the concept under study can be presented and commented on by students. Further research could develop this work further by exploring whether the same principles could apply to the transition between first, second and final years of study and then to the transition between $\mathrm{HE}$ and employment.

\section{References}

Archer, L. 2007. Diversity, equality and higher education: A critical reflection on the abuses of equity discourse within widening participation. Teaching in Higher Education, 12(5-6), 635- 653.

Askham, P. 2008. Context and identity: Exploring adult learners experiences of higher education. Journal of Further and Higher Education, 32(1), 85-97.

Bandura, A. 1997. Self-efficacy: Toward a unifying theory of behaviour change. Psychological Review, (84), 191-195.

Bryman, B. and Bell, E. 2011. Business Research Methods, 3rd ed., Oxford: Oxford University Press.

Finch, D., Nadeau, J. and O'Reilly, N. 2012. The future of marketing education: a practitioner's perspective. Journal of Marketing Education, 35(1), 54-67.

Fisher R., Cavanagh, J. and Bowles, A. 2011. Assisting transition to university: using assessment as a formative learning tool. Assessment \& Evaluation in Higher Education, $36(2), 225-237$.

Gallander Wintre M., Dilouya, B., Pancer, M., Pratt M. W., Birnie-Lefcovitch, S., Polivy J. and Adams, G. 2011. Academic achievement in first-year university: who maintains their high school average? Higher Education, 62, 467-481. 
Goldfinch, J. and Hughes, M. 2007. Skills, learning styles and success of first-year undergraduates. Active Learning in Higher Education, 8(3), 259-273.

Haggis, T. 2006. Pedagogies for diversity: Retaining critical challenges amidst fears of 'dumbing down'. Studies in Higher Education, 31(5), 521-35.

Harrigan, P. and Hulbert, B. 2011. How can marketing academics serve marketing practice? The new marketing DNA as a model for marketing education. Journal of Marketing Education, 33(3) 253-272.

Hsieh, P., Sullivan, J. R. and Guerra, N. S. 2007. A closer look at college students; selfefficacy and Goal Orientation. Journal of Advanced Academics. , 18(3), 454-476.

Johnston, B. 2010. The first year at University - teaching students in Transition. Maidenhead: McGraw-Hill Education.

Leary, K. \& DeRosier, M. 2012. Factors Promoting Positive Adaptation and Resilience during the Transition to College. Journal of Psychology, 3(12A), 1215-1222.

Maunder, R., Cunliffe, M., Galvin, J., Mjali, S. \& Rogers, J. 2013. Listening to Student Voices: Student Researchers exploring undergraduate experiences of university transition. Higher Education, 66(2), 139 - 152.

McCabe, A. and O'Connor, U. 2014. Student-centred learning: the role and responsibility of the lecturer Teaching in Higher Education, 19(4), 350-359.

McMillan, W. 2014. They have different information about what is going on: Emotion in the transition to university. Higher Education Research \& Development, 33(6), 1123-1135.

Palmer, M., O'Kane, P. and Owens, M. 2009. Betwixt spaces: student accounts of turning point experiences in the first-year transition. Studies in Higher Education, 34(1), 37-54.

Peterson, R. M. and Dover, H. F. 2014. Building student networks with LinkedIn: the potential for connections, internships and jobs. Marketing Education Review. 24 (1), 15-20.

Pokorny, M. and Pokorny, H. 2005. Widening participation in higher education: student quantitative skills and independent learning as impediments to progression. International Journal of Mathematical Education in Science and Technology, 36(5), 445-467.

Prichard, R. 2006. British and German education students in a shifting scenario. Higher Education Management and Policy, 18(3), 1-23.

Robson, C. 2011. Real World Research. Third edition. Oxford, Blackwell

Schuller, T., Baron, S., and Field, T.(2000) 'Social Capital: A Review and Critique', in Baron, S., Field, J., and Schuller, T. (eds) (2000) Social Capital: Critical Perspectives. Oxford: Oxford University Press. 1-38.

Silverman, D. 2011. Interpreting Qualitative Data. Fourth edition. Sage, London.

Stephens, S., Balan, C.G. and Callaghan, S. 2010. Theory and practice: the experience of marketing graduates. Education and Training, 52(6/7), 552-560.

Tangey, S. 2014. Student-Centred learning: a humanist perspective. Teaching In Higher Education 19(3), 266-275. 
Tett, L. and Maclachlan, K. 2007. Adult literacy and numeracy, social capital, learner identities and self-confidence. Studies in the Education of Adults, 39(2), 150-167.

Tinto, V. 2003. Establishing Conditions for Student Success. Improving Completion Rates among Disadvantaged Students, edited by L. Thomas, M. Cooper and J. Quinn, 1-10. Stokeon-Trent: Trentham Books.

Tracy, S.J. 2013 Qualitative Research Methods: Collecting Evidence, Crafting Analysis, Communicating Impact. Wiley Blackwell, Chichester.

Turner, N.K. 2014.Development of self-belief for employability in higher education:ability, efficacy and control in context. Teaching in Higher Education, 19 (6), 592-602.

Walton, G. and Cohen, G. 2007. A question of belonging: Race, Social fit and Achievement. Journal of Personality and Psychology, 92(1), 82-96.

Zajacova, A., Lynch, S.M. and Espenshade, T.J. 2005. Self-efficacy, stress, and academic success in college. Research in Higher Education, 46(6), 677-706. 